\title{
1 High pressure inside nanometre-sized particles influences the rate 2 and products of chemical reactions
}

3 Matthieu Riva ${ }^{\dagger, *}$, Jianfeng Sun ${ }^{\dagger,}$, V. Faye McNeill", Charline Ragon ${ }^{\dagger}$, Sebastien Perrier ${ }^{\dagger}$, Yinon

4 Rudich $^{\perp}$, Sergey A. Nizkorodov ${ }^{\#}$, Jianmin Chen $^{\S}$, Frederic Caupin ${ }^{\nabla}$, Thorsten Hoffmann ${ }^{\circ, *}$, Christian 5 George ${ }^{\dagger, *}$

6 Univ. Lyon, Université Claude Bernard Lyon 1, CNRS, IRCELYON, F-69626, Villeurbanne, France.

7 S Shanghai Key Laboratory of Atmospheric Particle Pollution and Prevention (LAP3), Department of 8 Environmental Science \& Engineering, Fudan University, Shanghai 200433, China.

9 " Department of Chemical Engineering and Department of Earth and Environmental Sciences, 10 Columbia University, New York, NY 10025 USA

$11 \perp$ Department of Earth and Planetary Sciences, Weizmann Institute, Rehovot 76100, Israel.

$12{ }^{\#}$ Department of Chemistry, University of California, Irvine, CA 92694, USA.

$13{ }^{\nabla}$ Université de Lyon, Université Claude Bernard Lyon 1, CNRS, Institut Lumière Matière, F-69622, 14 Villeurbanne, France.

$15{ }^{\circ}$ Department of Chemistry, Johannes Gutenberg-Universität, Mainz, Germany.

16 Keywords: SOA, mass spectrometry, heterogeneous chemistry, pressure, new particle 17 formation 


\section{Abstract}

19 The composition of organic aerosol has a pivotal influence on aerosol properties such as toxicity, and

20 cloud droplets formation capability, which could affect both climate and air quality. However, a

21 comprehensive and fundamental understanding of the chemical and physical processes that occur in

22 nanometre-sized atmospheric particles remains a challenge that severely limits the quantification and

23 predictive capabilities of aerosol formation pathways. Here, we investigated the effects of a

24 fundamental and hitherto unconsidered physical property of nanoparticles - the Laplace pressure. By

25 studying the reaction of glyoxal with ammonium sulphate, both ubiquitous and important atmospheric

26 constituents, we show that high pressure can significantly affect the chemical processes that occur in

27 atmospheric ultrafine particles (i.e., particles $<100 \mathrm{~nm}$ ). Using high-resolution mass spectrometry and

28 UV/Vis spectroscopy, we demonstrated that the formation of reaction products is strongly (i.e., up to a

29 factor of 2) slowed down under high pressures typical of atmospheric nanoparticles. A size-dependent

30 relative rate constant is determined and numerical simulations illustrate the reduction in the production

31 of the main glyoxal reaction products. These results established that the high pressure inside

32 nanometre-sized aerosols must be considered as a key property that significantly impacts chemical

33 processes that govern atmospheric aerosol growth and evolution.

\section{Short Synopsis}

36 High pressure reached inside atmospheric nanometre-sized particles affects their chemistry and therefore their formation and growth. 


\section{Introduction}

Aerosol particles are a ubiquitous component of the atmosphere, comprising small liquid and solid particles suspended in the air, with diameters that vary from a few nanometres (nm) to several tens of micrometres $(\mu \mathrm{m}) .{ }^{1}$ Fine atmospheric aerosols $\left(\mathrm{PM}_{2.5}\right.$, particles with aerodynamic diameter $\left.\leq 2.5 \mu \mathrm{m}\right)$ produce a significant cooling effect in the atmosphere ${ }^{1-3}$ through two mechanisms: by directly reflecting solar radiation back into space, and by acting as nuclei for the formation of cloud droplets, thereby regulating cloud reflectivity and lifetime. ${ }^{2,3} \mathrm{PM}_{2.5}$ also has a negative impact on air quality and human health, representing the fifth ranking human health risk factor globally. ${ }^{4}$ Fine atmospheric aerosols can either be emitted directly into the air as primary aerosol, or formed in the atmosphere by gas-to-particle conversion and classified as secondary aerosol. ${ }^{1,5}$ The chemical composition of primary and secondary aerosols is mainly dominated by organic and inorganic species (and water at high relative humidity).While the inorganic species are limited to a few compounds (e.g., sulphates and nitrates are the largest contributors to submicron aerosol mass globally), there are thousands of organic compounds in aerosols. ${ }^{6}$ The organic vapours able to grow aerosols by condensation, thus forming "secondary organic aerosol" (SOA), are primarily formed through gas-phase oxidation of volatile organic compounds (VOC) emitted from biogenic and anthropogenic sources. ${ }^{1,5}$ However, the precise components and physicochemical processes involved remain poorly understood. Improving our fundamental knowledge of the chemical and physical processes that govern atmospheric aerosol growth and evolution is crucial to better quantify aerosol growth and properties and hence the effect of aerosols on climate change and impact on air quality.

While research is mainly focused on elucidating the processes that control the formation and evolution of SOA, one of the most fundamental properties - the pressure inside atmospheric particles - is currently neglected in aerosol formation and growth models. The Laplace pressure is of central importance for the thermodynamic description of liquids with strongly curved interfaces (i.e., nanoparticles and nanoscale droplets). It represents the pressure difference of a droplet between the inside and outside. This effect is produced due to surface tension at the interface between a liquid and the gas interface of a curved surface. ${ }^{7}$ The Laplace pressure is proportional to the surface tension and 
the inverse of the droplet size. ${ }^{7}$ The pressure is a fundamental physical quantity that affects the values of various thermodynamic and kinetic constants of numerous chemical reactions. ${ }^{8}$ The crucial parameters to describe the influence of pressure on chemical reactions can be further broken down, namely the reaction volume $(\Delta \mathrm{V})$ and the volume of activation $(\Delta \ddagger \mathrm{V})$. The volume of activation $\Delta \ddagger \mathrm{V}$ is the volume change of the reaction system from the reactants to transition state, and the reaction volume $\Delta \mathrm{V}$ is the corresponding volume change from the reactants to the products. The former has been studied in particular by Evans and Polanyi in their development of the transition state theory. ${ }^{9}$ As a result, the Laplace pressure is expected to have strong effects on the equilibrium state of any chemical system and may either accelerate or slow a given reaction. In general, processes that lead to a net increase in the molar volume from reactants to products (i.e., $\Delta \mathrm{V}>0$ ) are thermodynamically suppressed at high pressure, and processes with a positive volume of activation from reactants to transition state are kinetically suppressed at high pressures. ${ }^{10}$

To investigate the influence of the internal pressure on atmospherically relevant systems, we have considered a well-studied reaction of glyoxal and ammonium sulphate. Glyoxal is among the most abundant oxygenated VOC produced in the atmosphere from the oxidation of biogenic and anthropogenic organic precursors. ${ }^{11}$ While it was previously considered as too volatile to contribute to SOA formation, recent studies have shown that glyoxal and other small dicarbonyl species can significantly contribute to SOA growth through multiphase chemistry. ${ }^{12-18}$ Since these species are largely produced in the gas phase, condensed phase sinks help explaining an important part of the missing SOA mass predicted by simulations. ${ }^{17,23}$ In the presence of ammonium sulphate these multiphase processes produce light-absorbing complex organic compounds, that contain an imidazole function..$^{12,19,20,24}$ The vast majority of the kinetic studies characterizing atmospheric chemical reactions are conducted in bulk solution, ${ }^{22}$ and/or in large aerosols, ${ }^{18}$ hence earlier studies on glyoxal chemistry were performed at atmospheric pressure. To demonstrate the potential importance of the internal pressure for atmospheric chemical reactions, this study has focused on the chemical characterization of glyoxal chemistry at pressures that simulate the interior of atmospheric nanoparticles (i.e., $<100 \mathrm{~nm}$ ). 


\section{Experimental Methods}

93 The experiments were performed using individual low-density polyethylene bags (VWR). $10 \mathrm{~mL}$ bulk

94 samples were introduced into the bags, that were sealed without any air. The solutions mixtures contained $2 \mathrm{M}$ ammonium sulphate $\left(\left(\mathrm{NH}_{4}\right)_{2} \mathrm{SO}_{4} ;(99.0 \%\right.$, Sigma Aldrich) and 0.25-2 $\mathrm{M}$ of glyoxal (40\% in water, Sigma Aldrich), corresponding to a pH of 4. Experimental conditions were selected based on earlier studies which investigated the reaction of glyoxal with ammonium. Although these conditions do not mimic ambient concentrations, we selected this model system and reproduced the currently accepted conditions used in other studies and modified only the pressure at which the reaction took place. For each experiment, two sets of samples were prepared: i) "control” samples were protected from ambient light and kept at room temperature and at atmospheric pressure; ii) "pressure" samples were introduced into a high-pressure closed vessel (or reactor) and pressurized using water at 12.5, 25 or $50 \mathrm{MPa}$ at room temperature (Figure S1). The 5 bags containing 4 concentrations and 1 control were pressurized in a high-pressure vessel (OC-1; High Pressure Equipment Company, Erie, Pennsylvania) by a piston screw pump (Top Industry, France). Once the piston reached the desired pressure, the high-pressure vessel was isolated (using valves) in order to obtain a stable pressure during the experiment. The pressure inside the vessel was continuously monitored and remained stable (i.e., less than 5\% decrease over each experiment). One set of samples comprises four solutions containing glyoxal $(0.25,0.5,1$ and $2 \mathrm{M})$ and $\left(\mathrm{NH}_{4}\right)_{2} \mathrm{SO}_{4}$ (2M), 1 solution containing only glyoxal ( $2 \mathrm{M})$ and one water blank. The blanks were used to identify possible contamination from the bag itself. The results showed that the bags were not degraded by the

112 chemicals (organics, acids, etc.) used in the experiments. The samples were maintained for 3, 6, 12, 18 113 and 24-h. At least three replicates for each condition (concentration, exposure time and pressure) were 114 performed.

115 UV/Vis characterization. Kinetic analyses were based on measurements of the absorbance of the 116 reaction mixtures as a function of time over 200-900 $\mathrm{nm}$ with a UV/Vis spectrometer (Cary 60, 117 Agilent Technology). Directly after the end of the experiments, the samples were diluted (by a factor 118 of 10) in deionized water to stop/significantly slow down the glyoxal reaction and ensure an optimal 
quantification (i.e., peak absorbance $<1$ ). The diluted reaction mixtures were taken and placed into 1

cm quartz cuvettes. Control experiments were performed (i.e., without dilution) to ensure that the dilution did not modify the composition of the reaction mixtures. The ratio of the peak absorbance of the solution at high pressure and at atmospheric pressure were similar with (e.g., ratio $=0.52,2 \mathrm{Mat} 50$ $\mathrm{MPa}$ ) and without dilution (ratio $=0.56 ; 2 \mathrm{M}$ at $50 \mathrm{MPa}$ ). The absorption band between $260 \mathrm{~nm}$ and $300 \mathrm{~nm}$ was used to probe the formation of light-absorbing compounds produced from the reaction of glyoxal with ammonium ions. Note that using the analytical techniques employed in this study, it was not possible to directly monitor the reactants' concentrations. Therefore, no quantitative data on the

127 thermodynamics were obtained.

128 Chemical characterization. Solutions exposed at atmospheric pressure and at high pressures were directly diluted $(\times 10,000)$ at the end of the experiments to stop the reaction. Diluted samples were analysed by ultra-high performance liquid chromatography (Dionex 3000, Thermo Scientific) using a Waters Acquity HSS C18 column $(1.8 \mu \mathrm{L}, 100$ x 2.1mm) coupled with a Q-Exactive Hybrid Quadrupole-Orbitrap mass spectrometer (Thermo Scientific) equipped with an electrospray ionization (ESI) source operated in negative and positive modes. The mobile phase consisted of (A) $0.1 \%$ formic acid in water (Optima ${ }^{\circledR}$ LC/MS, Fischer Scientific) and (B) $0.1 \%$ formic acid in acetonitrile (Optima ${ }^{\circledR}$ LC/MS, Fischer Scientific). Gradient elution was carried out by the $\mathrm{A} / \mathrm{B}$ mixture at a total flow rate of $300 \mu \mathrm{L} / \mathrm{min}$ : $1 \%$ of B for $2 \mathrm{~min}$, a linear gradient was used until $100 \%$ of B for $11 \mathrm{~min}$, then $100 \%$ of B for 2 min and back to $1 \%$ of B in 0.1 min, and to end $1 \%$ of B for 6.9 min. Caffeine was used as an internal standard to retrieve the ionization efficiency of the different samples in order to account for the variability of the UPLC/ESI-Orbitrap. The recovery of caffeine was $86 \pm 5 \%$ (1 std. dev.) and each sample was corrected for the instrumental variability.

141 GAMMA simulations. Calculations were performed using the photochemical box model GAMMA $1425.0^{25,26}$ to simulate the formation of light-absorbing organic material in aqueous aerosols from glyoxal 143 following Woo et al. ${ }^{27}$ GAMMA uses a detailed kinetic treatment of glyoxal chemistry and does not assume chemical equilibrium. ${ }^{25}$ Gas phase concentration of glyoxal was set to $4.68 \times 10^{9}$ molecule $\mathrm{cm}^{-3}$

145 as previously used by Tsui et al. ${ }^{26}$ The reaction of aqueous glyoxal with $\mathrm{NH}_{4}{ }^{+}$to form light-absorbing 146 organic species was simulated using the kinetics of Schwier et al. ${ }^{28}$ for the base case and compared 
147 with simulations where that overall rate constant was reduced to account for the effects of particle

148 pressure following the data in Figure 3. Simulations were performed for ammonium (bi)sulfate

149 particles at $65 \% \mathrm{RH}$ and $\mathrm{pH} 2$ with a diameter of $20,40,80,160$, or $320 \mathrm{~nm}$, with a constant liquid

150 water content $\left(7.25 \times 10^{12} \mathrm{~cm}^{3} \mathrm{~cm}^{-3}\right)$ and surface area density $\left(10^{-4} \mathrm{~cm}^{2} \mathrm{~cm}^{-3}\right)$. No partitioning correction

151 was applied to take into consideration the possible Kelvin effect. In other words, to evaluate the effect

152 of the pressure, identical aqueous phase concentration of glyoxal was considered for the different size

153 bins. A 12-hour time period (dawn to dusk) was simulated. Ambient temperature was set to vary

154 sinusoidally through the day with a half-period of $12 \mathrm{~h}$, with the minimum temperature $298.15 \mathrm{~K}$ at

155 dawn and dusk and maximum temperature $303.15 \mathrm{~K}$ at midday. Photochemical rate constants were set

156 following McNeill et al. ${ }^{25}$

\section{Results and Discussion}

158 Influence of pressure on the formation of glyoxal reaction products. Assuming a liquid particle

159 and the known surface tension $(\gamma)$ (e.g., $72.74 \mathrm{mN} \mathrm{m}^{-1}$ for water, $44.4 \mathrm{mN} \mathrm{m}^{-1}$ for SOA at $20^{\circ} \mathrm{C}$ ), ${ }^{29}$ the

160 effective pressure inside nanometre-sized particles can be calculated using the Young-Laplace

161 equation ( $\Delta \mathrm{P}=2 \gamma / \mathrm{r}$, with $\mathrm{r}$ representing the radius of the particle) (Figure 1A). It should be pointed

162 out the surface tension of nanoparticles remains basically unknown and only the surface tension of

163 large aerosols can be determined. Hence, surface tension of alpha-pinene-derived SOA and pure water

164 were selected as lower and upper limits, respectively, to probe the impact of the pressure. Indeed,

165 earlier studies have shown that atmospherically relevant particles, including inorganic and organic

166 species, have surface tension within this range..$^{29-33}$ Besides surface tension, other parameters can

167 influence the pressure, such as the phase state and/or chemical composition of the particles. For

168 example, the surface tension of dissolved SOA from the oxidation of biogenic compounds can be

169 reduced by a factor of two compared to pure water. ${ }^{29}$ According to various studies, biogenic SOA

170 particles produced in laboratory chambers or observed in the ambient atmosphere may exist in various

171 solid and liquid forms. ${ }^{34-36}$ However, nanometre-sized organic aerosols remain liquid under most

172 environmental conditions. ${ }^{36-38}$ To investigate the impact of pressure on atmospheric chemical reactions

173 that occur within the particles, we studied the reaction between glyoxal and ammonium sulphate under 
different pressures ranging from 1 atm to 500 atm: $0.1,12.5,25$ and $50 \mathrm{MPa}$, corresponding to coarse

175 particles and to fine aerosol particles of 23, 12 and $6 \mathrm{~nm}$ in diameter, respectively (diameters

176 calculated assuming a liquid droplet with a surface tension of pure water). As previously reported,

177 products formed from the glyoxal-ammonium sulphate reaction absorb light in the UV and visible

178 wavelengths providing a convenient way to follow the reaction (Figures 1 and S1-S4). ${ }^{19,20,39}$ Figure 1B

179 shows the time evolution of the UV absorption spectra of a solution initially containing $0.25,0.5,1$

180 and $2 \mathrm{M}$ glyoxal mixed with $2 \mathrm{M}$ of ammonium sulphate $\left(\left(\mathrm{NH}_{4}\right)_{2} \mathrm{SO}_{4}\right)$ up to 24 hours, corresponding

181 to experimental conditions conducted under atmospheric pressure (i.e., 1 atm internal pressure). ${ }^{20}$ The

182 resulting solution is weakly acidic $(\mathrm{pH} \sim 4)$, thus simulating aqueous tropospheric aerosol particles.

183 The absorbance of solutions at atmospheric pressure increased with time. Under high pressures, a

184 significant decrease in the total absorbance is observed for all conditions investigated in this study

185 (Figures 1C \& 1D; S2). Already after 3h, the difference between experiments conducted at

186 atmospheric pressure and $50 \mathrm{MPa}$ experiments is significant (i.e., $\mathrm{Abs}_{\mathrm{P} 50} / \mathrm{Abs}_{\mathrm{P} 0.1}=0.66 \pm 0.02$ )

187 underlying the impact of increased pressure on the rate of glyoxal's reaction under slightly acidic

188 aqueous conditions. Interestingly, related reactions between carbonyls and amines have been studied

189 in the context of food science and a retarding effect of high (400 MPa) pressure was demonstrated. ${ }^{40-}$

$190 \quad 42$ This observation is consistent with our results, although we find an effect on the reaction of glyoxal

191 with ammonium sulphate at much milder pressures e.g., a slowing down by a factor of 2 at $25 \mathrm{MPa}$.

192 This proves that pressure can already have a pronounced effect in a relevant size range for atmospheric

193 aerosols. It is important to point out that in this study we have explored the effect of the pressure in

194 bulk solution in a closed system, i.e., no partitioning was considered. As a result, the decreasing rate

195 constant is only due to the effect of the pressure on the chemical processes. Additional studies are

196 required to relate what we observed in bulk solution to aerosol particles.

197 Ultra-performance liquid chromatography coupled with hybrid quadrupole Orbitrap mass

198 spectrometry analysis, performed in negative and positive modes, shows the presence of a wide

199 variety of reaction products (Figure 2A). The major reaction products, detected by their protonated

200 ions and consistent with other studies that form through the iminum pathway, ${ }^{19,20,22,24,43}$ (i.e., imidazole

$201\left(\mathrm{C}_{3} \mathrm{H}_{5} \mathrm{~N}_{2}{ }^{+}\right)$, imidazole-2-carboxaldehyde $\left(\mathrm{C}_{4} \mathrm{H}_{5} \mathrm{ON}_{2}{ }^{+}\right)$, hydrated imidazole-2-carboxaldehyde 
$\left.\left(\mathrm{C}_{4} \mathrm{H}_{7} \mathrm{O}_{2} \mathrm{~N}_{2}^{+}\right)\right)$, are observed in all the experiments. This product distribution is consistent with the

203

204

205

206

207

208

209

210

211

212

213

214

215

216

217

218

219

220

221

222

223

224

225

226

227

228

existing literature, where high-molecular-weight organic compounds, formed by accretion reactions, have been observed. ${ }^{12,19,20,43}$ Although the reaction products are similar in our study, samples exposed to high pressures exhibit much lower product yields compared to the atmospheric pressure samples (Figure 2A). More specifically, concentrations of the primary products, such as imidazole, reduced by a factor of 2 after 24 hours, further highlighting the impact of pressure on this chemical system (Figure 2B). As in the Maillard reaction, ${ }^{41,44}$ chemical processes leading to the formation of such products increase the volume of reaction (i.e., $\Delta \mathrm{V}>0$ ). Therefore, at higher pressure, the product formation is reduced. In addition, formation of N-containing oligomers is also significantly supressed by the pressure ( 40\% after $24 \mathrm{~h})$. For example, the formation of $\mathrm{C}_{6} \mathrm{H}_{10} \mathrm{O}_{6} \mathrm{~N}^{+}$dimer is strongly reduced under high pressures (Figure 2). Finally, it is noted that the glyoxal products formed from aldol/acetal oligomerization were not observed in either the atmospheric pressure or the high-pressure samples. Overall, the results obtained in this study reveal that the Laplace pressure, i.e., the pressure within atmospheric particles, can strongly influence the multiphase processes involved in the formation and growth of SOA.

Particle size-dependence kinetics. As the light-absorbing compounds absorb light at $290 \mathrm{~nm}$ (Figure S3), monitoring the evolution of this absorbance band provides insight into the overall kinetics of the reaction between glyoxal and ammonium cations. The reactions are first order (Figure S4) within the first 24 hours, which is consistent with an earlier study. ${ }^{20}$ Therefore, for each set of experiments (i.e., four concentrations at a given pressure and four concentrations at atmospheric pressure), where each condition was repeated at least three times, a global rate constant $\left(k_{o b s}\right)$ can be obtained. As shown in Figure 3A, a pressure-dependent rate constant is determined, using the average $k_{o b s}$ determined for each pressure. Using linear regression, particle size-dependence of the rate constant can be obtained, as shown in Figure 3B. Two surface tension values were selected to obtain the rate constant as a function of particle size: the surface tension of water $\left(72.74 \mathrm{mN} \mathrm{m}^{-1}\right)$, which represents an upper limit, and the surface tension of $\alpha$-pinene SOA, which is formed under humid conditions $\left(44.4 \mathrm{mN} \mathrm{m}^{-1}\right){ }^{29}$ $\alpha$-pinene-derived SOA is used as model SOA because monoterpenes are among the most important 
229 SOA precursors on a global scale..$^{45,46}$ Therefore, for ultrafine particles, i.e., $<100 \mathrm{~nm}$, the reduction

230 of glyoxal chemistry is important, indicating that chemical processes identical or similar to those

231 involved in the heterogeneous chemistry of the dicarbonyls, can be strongly reduced in ultrafine

232 atmospheric aerosols.

233 To further illustrate particle size-dependence chemistry, the photochemical box model

234 GAMMA was used to simulate imidazole formation as a function of particle size (and hence pressure),

235 The calculations were performed in discrete size bins (i.e., 20, 40, 80, 160, and $320 \mathrm{~nm}$ ), for 12 hours

236 (Figure 4)..$^{25,27,47}$ The simulations show that the pressure effect on the formation of imidazole and other

237 brown carbon species is negligible, for the largest size bin (i.e., $320 \mathrm{~nm}$ ). However, the heterogeneous

238 process is greatly reduced when the pressure within the nanometre-sized particles increases. For

239 example, the formation of glyoxal reaction products is reduced by $20 \%$ for the smallest size bin (i.e.,

$24020 \mathrm{~nm}$ ). This further underlines that chemical processes that are expected to grow ultrafine particles ${ }^{48}$

241 are likely to be strongly influenced by their high internal pressure.

242 By studying an important chemical reaction under relevant atmospheric conditions, we showed that

243 the high pressure inside nanometre-sized aerosol particles is a key property that has not been

244 considered hitherto and that can have a significant influence on the chemical processes governing

245 atmospheric particle growth and evolution. More importantly we demonstrated that pressures can have

246 a noticeable effect at much milder pressures ( 1-2 order of magnitude lower) than has been studied

247 before. Such pressures are highly relevant for atmospheric aerosols. However, it is important to note

248 that due to the relative short lifetime of nanoparticles (i.e., from a few hours to a day), the pressure

249 would have a noticeable effect for chemical reactions that are greatly impacted by the Laplace

250 pressure with rate constant comparable or shorter than the aerosol lifetime. Considering the Evans-

251 Polanyi principle, Le Noble and co-workers ${ }^{49}$ have derived a function to represent the reaction profile

252 for a one-step reaction. By using such an approach, it is possible to evaluate the impact of the pressure

253 on changes in the transition state. As we studied a global reaction, it was not possible to isolate a

254 single reaction step using the analytical techniques employed by Le Noble et al. ${ }^{49}$ However, based on

255 the existing literature we can derive some information providing hints that identify which reaction step

256 may have been mostly impacted by the pressure. ${ }^{8,50}$ For example, the breaking of bonds within a 
257 reaction mechanism involves the separation of atoms from each other from covalent distances to van

258 der Waals distances. In fact, the transformation of $\mathrm{NH}_{4}{ }^{+}$to $\mathrm{H}^{+}$and $\mathrm{NH}_{3}$, which was identified to be a

259 key state of the investigated chemistry, ${ }^{19,24}$ is known to be hindered by pressure (i.e., $\Delta \mathrm{V}=7 \mathrm{~cm}^{3} \mathrm{~mol}^{-}$

$\left.260{ }^{1}\right)^{50,51}$, and might explain the observation made here. While we found a negative effect here for this

261 specific reaction on the formation and growth of SOA, other potentially important particle phase

262 reactions, especially those with negative reaction volumes and/or negative activation volumes, could

263 be strongly promoted by pressure. ${ }^{1,22}$ The extensive literature on the effects of pressure on organic and

264 inorganic chemical reactions in solutions strongly suggests that several types of atmospheric reactions

265 could also be influenced by pressure. ${ }^{8}$ For example, nucleophilic substitution reactions of various

266 types of organic compounds at high pressure are favoured because ionisation reactions in the transition

267 state of the reaction cause negative activation volumes. While the experiments performed in this work

268 show a clear impact of the pressure, additional experiments using aerosol droplets are required to further

269 confirm the results presented here. Indeed, interfacial chemistry, gas-liquid exchanges i.e., processes not

270 considered here, may also be affected by the pressure in addition to the "bulk" chemical reaction kinetics

271 and equilibria. Overall, our results provide information about the potentially critical influence of

272 pressure on the chemistry occurring within atmospheric nanoparticles. While such processes have not

273 been reported before, this work emphasizes the need to consider particle phase processing under

274 atmospherically relevant conditions.

275 
A

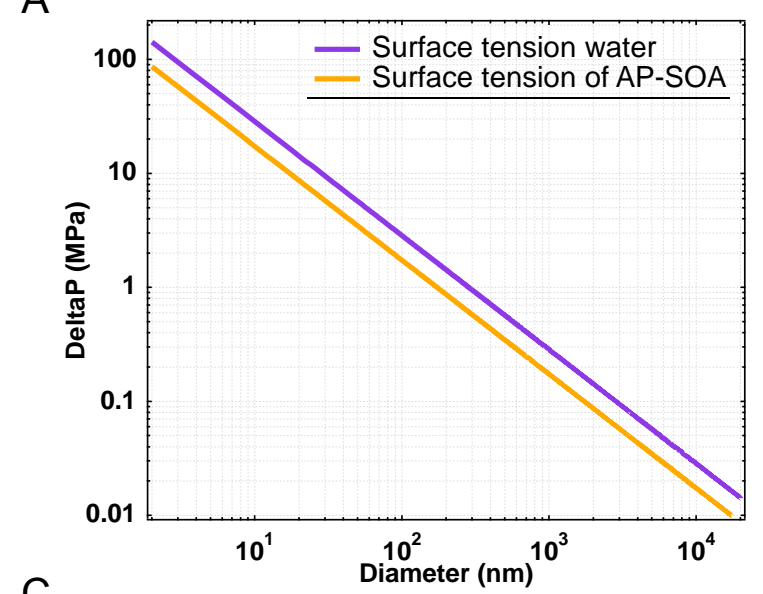

C

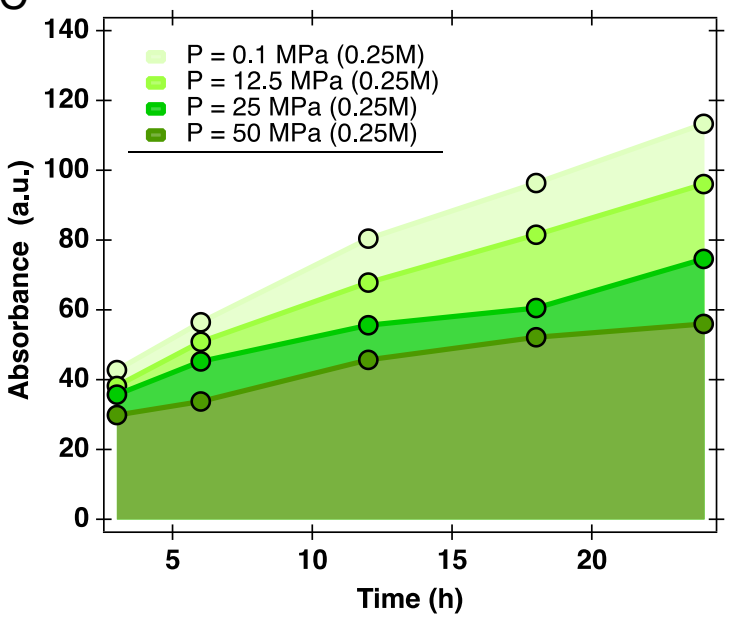

B
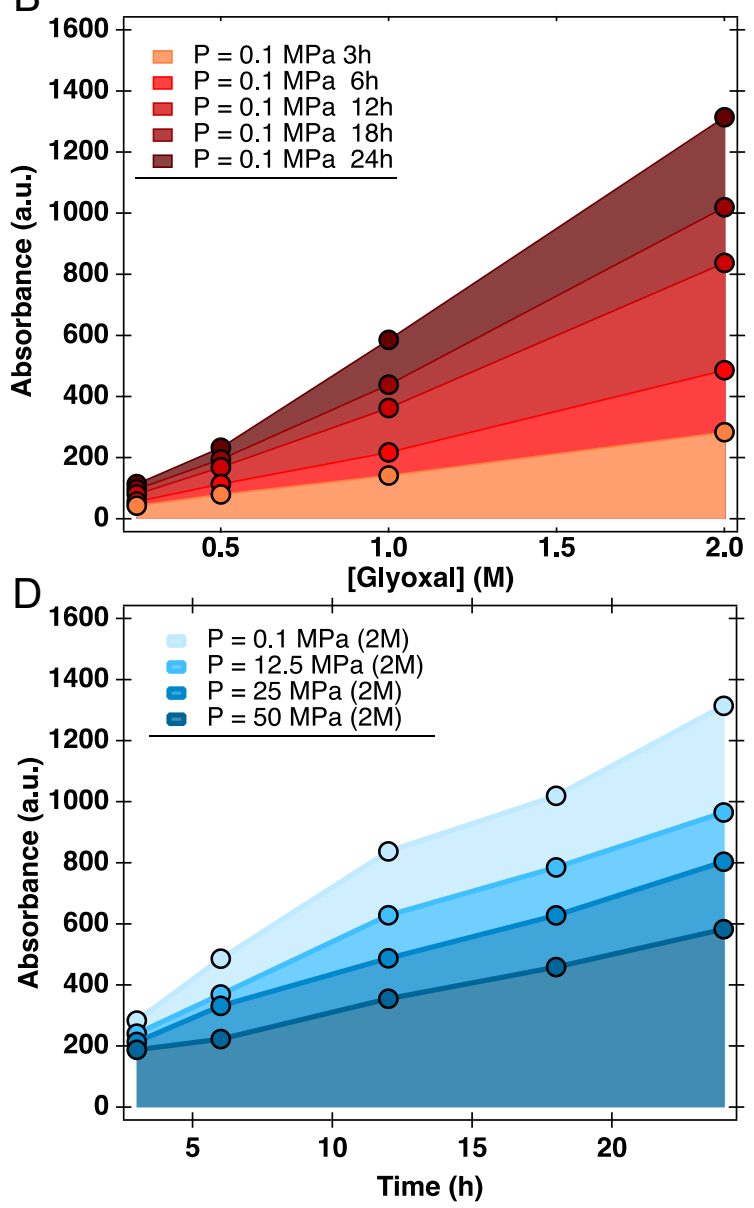

278 Figure 1. (A) Pressure inside 2 to $1000 \mathrm{~nm}$ aerosol particles with surface tension of water and $\alpha$-pinene

279 SOA. (B) Evolution of the absorbance (non-cumulative) of light-absorbing glyoxal reaction products at

280 different reaction time and as function of glyoxal concentration. Non-cumulative absorbance of light-

281 absorbing glyoxal reaction products at different pressures of (C) $0.25 \mathrm{M}$ glyoxal/ $2 \mathrm{M}$ AS and (D) $2 \mathrm{M}$

282 glyoxal/ 2 M AS as a function of reaction time. 
A

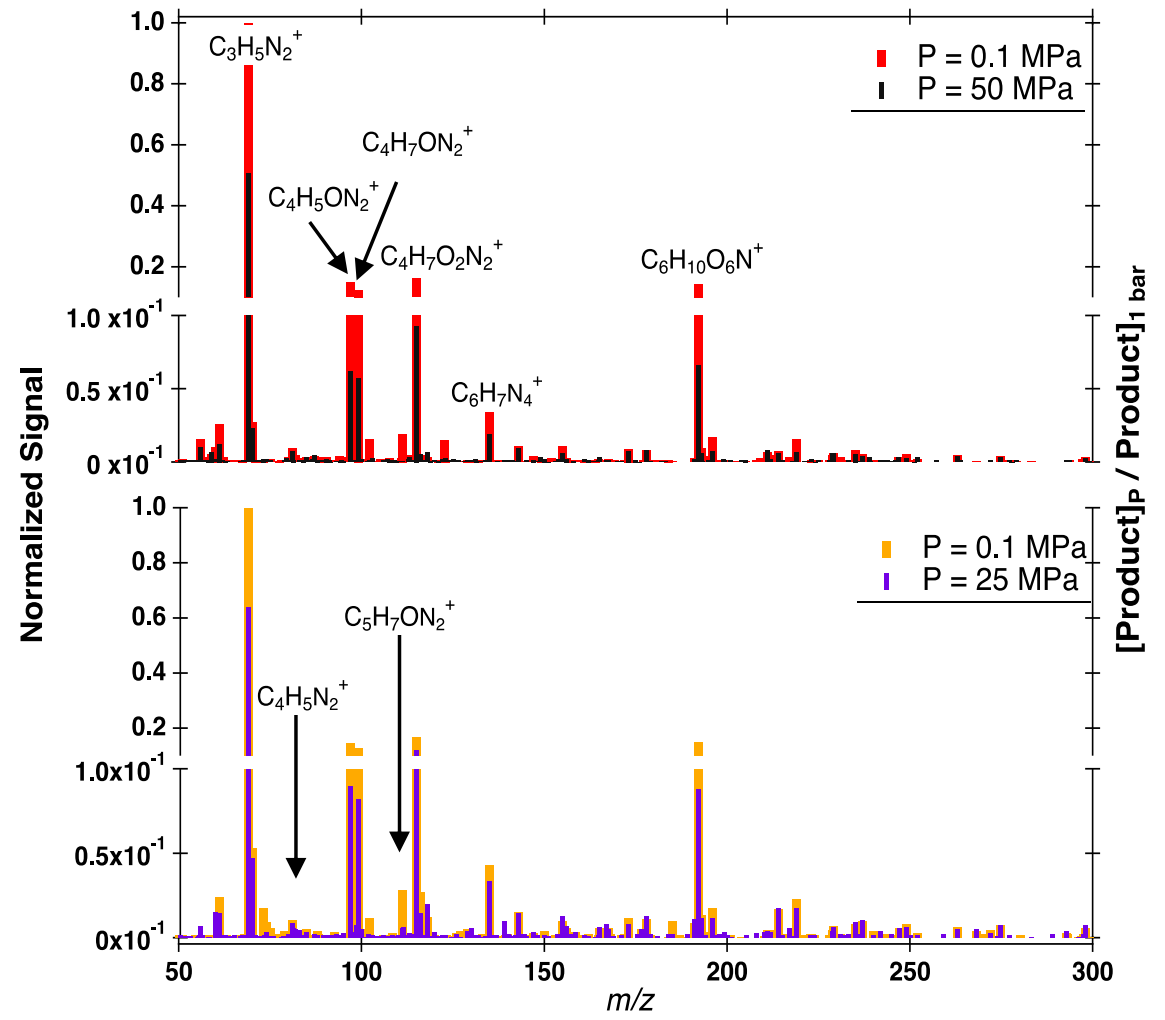

B

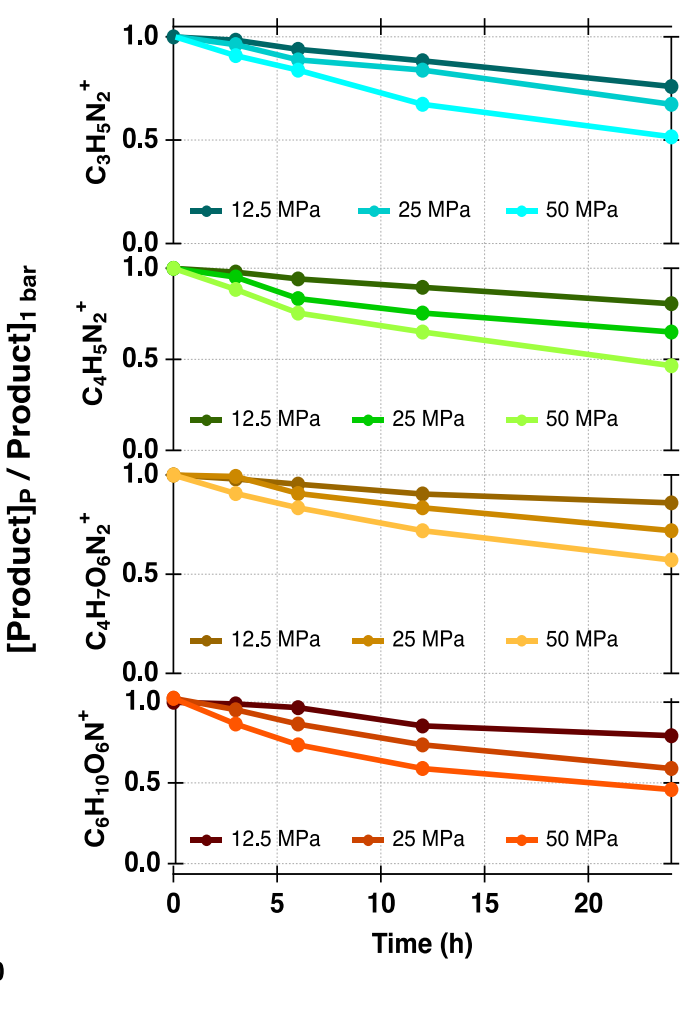

283 Figure 2. (A) Impact of the pressure on the chemical composition of organic products from the reaction 284 of glyoxal with ammonium sulphate measured by UPLC-(+)ESI-Orbitrap. Mass spectra were averaged 285 across the chromatogram and background subtracted (i.e., water samples served as blank). (B) Evolution 286 of the relative concentration ([Product $]_{\mathrm{P} \gg 1 \text { atm }} /[\text { Product }]_{\mathrm{P}=1 \mathrm{~atm}}$ ) of the main reaction products as a 287 function of time. 
A

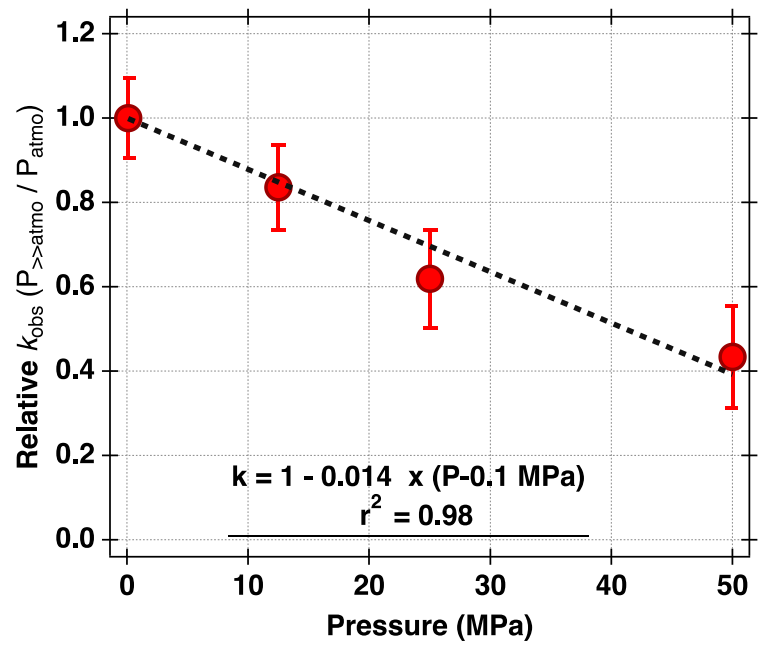

$\mathrm{B}$

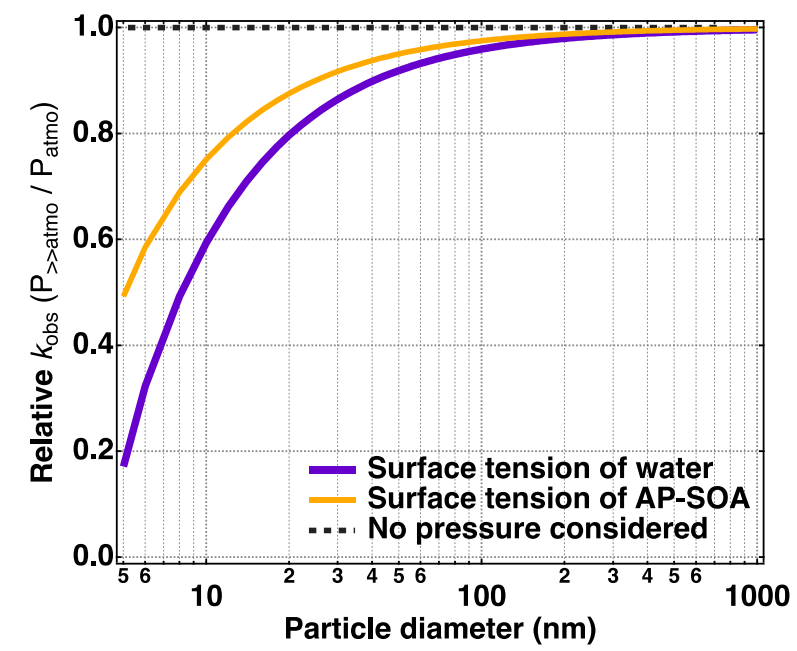

289

290 Figure 3. (A) Relative glyoxal/AS reaction rate constant of light-absorbing product formation as a

291 function of pressure. The overall uncertainty of the relative rate constant is 0.074 (one standard

292 deviation). (B) Relative glyoxal/AS reaction rate constant as a function of aerosol particle diameter 293 considering different aerosol surface tension.

294 


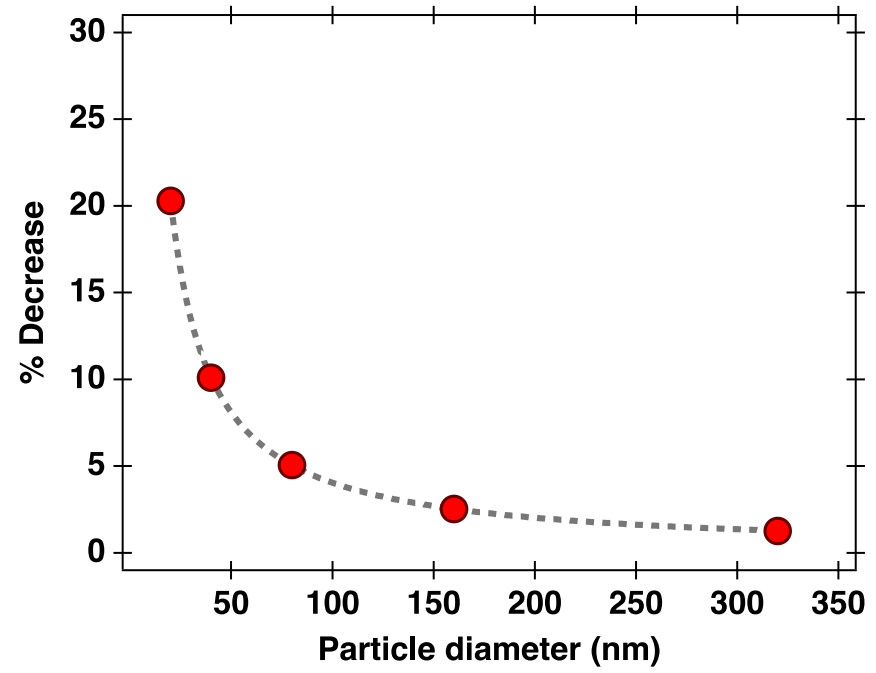

296 Figure 4. Decrease of the formation of glyoxal reaction products as a function of particle size

297 diameter. Simulations were performed using GAMMA for different size bins diameters (e.g., 20, 40,

29880,160 , and $320 \mathrm{~nm}$ ) and under Eastern US rural conditions. 
300 Figure S1 shows the absorbance of light-absorbing glyoxal oxidation products at different reaction

301 time and pressure. Figure S2 displays the relative absorbance of light-absorbing glyoxal oxidation

302 products under the different experimental conditions used in this study. Figure S3 shows the

303 absorption spectra of glyoxal products after 24 hours. Figure S4 shows the first-order kinetic fit for the

304 different experiments performed in this study. This material is available free of charge via the Internet

305 at http://pubs.acs.org/.

306

307 AUTHOR INFORMATION

308 Corresponding Author

$309 *$ E-mail (M. R.): matthieu.riva@ircelyon.univ-lyon1.fr

$310 *$ E-mail (T. H.): t.hoffmann@uni-mainz.de

$311 *$ E-mail (C. G.): christian.george@ircelyon.univ-lyon1.fr

\section{Funding Sources}

313 This work is funded in part by the European Research Council (ERC-StG MAARvEL, grant nr 852161),

314 and by the Deutsche Forschungsgemeinschaft (DFG, HO 1748/19-1)

\section{ACKNOWLEDGMENT}

317 The authors wish to thank the European Research Council (ERC-StG), the Deutsche

318 Forschungsgemeinschaft and the University of Lyon for financial support. S.A.N. thanks the Université

319 Claude Bernard Lyon 1 for providing him with a visiting professorship in the summer of 2018.

320 ASSOCIATED CONTENT

321 Figure S1 shows the experimental device (high-pressure vessel) used in this study. This material

322 is available free of charge via the Internet at http://pubs.acs.org/. 


\section{References}

325 (1) Hallquist, M.; Wenger, J. C.; Baltensperger, U.; Rudich, Y.; Simpson, D.; Claeys, M.; Dommen, J.; Donahue, N. M.; George, C.; Goldstein, A. H.; Hamilton, J. F.; Herrmann, H.; Hoffmann, T.; Iinuma, Y.; Jang, M.; Jenkin, M. E.; Jimenez, J. L.; Kiendler-Scharr, A.; Maenhaut, W.; McFiggans, G.; Mentel, Th. F.; Monod, A.; Prévôt, A. S. H.; Seinfeld, J. H.; Surratt, J. D.; Szmigielski, R.; Wildt, J. The Formation, Properties and Impact of Secondary Organic Aerosol: Current and Emerging Issues. Atmospheric Chemistry and Physics 2009, 9 (14), 5155-5236. https://doi.org/10.5194/acp-9-5155-2009.

(2) Albrecht, B. A. Aerosols, Cloud Microphysics, and Fractional Cloudiness. Science 1989, 245 (4923), 1227-1230. https://doi.org/10.1126/science.245.4923.1227.

(3) Twomey, S. The Influence of Pollution on the Shortwave Albedo of Clouds. Journal of the Atmospheric Sciences 1977, 34 (7), 1149-1152. https://doi.org/10.1175/15200469(1977)034<1149:TIOPOT>2.0.CO;2.

(4) Gakidou, E.; Afshin, A.; Abajobir, A. A.; Abate, K. H.; Abbafati, C.; Abbas, K. M.; AbdAllah, F.; Abdulle, A. M.; Abera, S. F.; Aboyans, V.; Abu-Raddad, L. J.; Abu-Rmeileh, N. M. E.; Abyu, G. Y.; Adedeji, I. A.; Adetokunboh, O.; Afarideh, M.; Agrawal, A.; Agrawal, S.; Ahmadieh, H.; Ahmed, M. B.; Aichour, M. T. E.; Aichour, A. N.; Aichour, I.; Akinyemi, R. O.; Akseer, N.; Alahdab, F.; Al-Aly, Z.; Alam, K.; Alam, N.; Alam, T.; Alasfoor, D.; Alene, K. A.; Ali, K.; AlizadehNavaei, R.; Alkerwi, A.; Alla, F.; Allebeck, P.; Al-Raddadi, R.; Alsharif, U.; Altirkawi, K. A.; AlvisGuzman, N.; Amare, A. T.; Amini, E.; Ammar, W.; Amoako, Y. A.; Ansari, H.; Antó, J. M.; Antonio, C. A. T.; Anwari, P.; Arian, N.; Ärnlöv, J.; Artaman, A.; Aryal, K. K.; Asayesh, H.; Asgedom, S. W.; Atey, T. M.; Avila-Burgos, L.; Avokpaho, E. F. G. A.; Awasthi, A.; Azzopardi, P.; Bacha, U.; Badawi, A.; Balakrishnan, K.; Ballew, S. H.; Barac, A.; Barber, R. M.; Barker-Collo, S. L.; Bärnighausen, T.; Barquera, S.; Barregard, L.; Barrero, L. H.; Batis, C.; Battle, K. E.; Baumgarner, B. R.; Baune, B. T.; Beardsley, J.; Bedi, N.; Beghi, E.; Bell, M. L.; Bennett, D. A.; Bennett, J. R.; Bensenor, I. M.; Berhane, A.; Berhe, D. F.; Bernabé, E.; Betsu, B. D.; Beuran, M.; Beyene, A. S.; Bhansali, A.; Bhutta, Z. A.; Bicer, B. K.; Bikbov, B.; Birungi, C.; Biryukov, S.; Blosser, C. D.; Boneya, D. J.; Bou-Orm, I. R.; Brauer, M.; Breitborde, N. J. K.; Brenner, H.; Brugha, T. S.; Bulto, L. N. B.; Butt, Z. A.; Cahuana-Hurtado, L.; Cárdenas, R.; Carrero, J. J.; Castañeda-Orjuela, C. A.; Catalá-López, F.; Cercy, K.; Chang, H.-Y.; Charlson, F. J.; Chimed-Ochir, O.; Chisumpa, V. H.; Chitheer, A. A.; Christensen, H.; Christopher, D. J.; Cirillo, M.; Cohen, A. J.; Comfort, H.; Cooper, C.; Coresh, J.; Cornaby, L.; Cortesi, P. A.; Criqui, M. H.; Crump, J. A.; Dandona, L.; Dandona, R.; das Neves, J.; Davey, G.; Davitoiu, D. V.; Davletov, K.; de Courten, B.; Defo, B. K.; Degenhardt, L.; Deiparine, S.; Dellavalle, R. P.; Deribe, K.; Deshpande, A.; Dharmaratne, S. D.; Ding, E. L.; Djalalinia, S.; Do, H. P.; Dokova, K.; Doku, D. T.; Donkelaar, A. van; Dorsey, E. R.; Driscoll, T. R.; Dubey, M.; Duncan, B. B.; Duncan, S.; Ebrahimi, H.; El-Khatib, Z. Z.; Enayati, A.; Endries, A. Y.; Ermakov, S. P.; Erskine, H. E.; Eshrati, B.; Eskandarieh, S.; Esteghamati, A.; Estep, K.; Faraon, E. J. A.; Farinha, C. S. e S.; Faro, A.; Farzadfar, F.; Fay, K.; Feigin, V. L.; Fereshtehnejad, S.-M.; Fernandes, J. C.; Ferrari, A. J.; Feyissa, T. R.; Filip, I.; Fischer, F.; Fitzmaurice, C.; Flaxman, A. D.; Foigt, N.; Foreman, K. J.; Frostad, J. J.; Fullman, N.; Fürst, T.; Furtado, J. M.; Ganji, M.; GarciaBasteiro, A. L.; Gebrehiwot, T. T.; Geleijnse, J. M.; Geleto, A.; Gemechu, B. L.; Gesesew, H. A.; Gething, P. W.; Ghajar, A.; Gibney, K. B.; Gill, P. S.; Gillum, R. F.; Giref, A. Z.; Gishu, M. D.; Giussani, G.; Godwin, W. W.; Gona, P. N.; Goodridge, A.; Gopalani, S. V.; Goryakin, Y.; Goulart, A. C.; Graetz, N.; Gugnani, H. C.; Guo, J.; Gupta, R.; Gupta, T.; Gupta, V.; Gutiérrez, R. A.; Hachinski, V.; Hafezi-Nejad, N.; Hailu, G. B.; Hamadeh, R. R.; Hamidi, S.; Hammami, M.; Handal, A. J.; Hankey, G. J.; Hanson, S. W.; Harb, H. L.; Hareri, H. A.; Hassanvand, M. S.; Havmoeller, R.; Hawley, C.; Hay, S. I.; Hedayati, M. T.; Hendrie, D.; Heredia-Pi, I. B.; Hernandez, J. C. M.; Hoek, H. W.; Horita, N.; Hosgood, H. D.; Hostiuc, S.; Hoy, D. G.; Hsairi, M.; Hu, G.; Huang, J. J.; Huang, H.; Ibrahim, N. M.; Iburg, K. M.; Ikeda, C.; Inoue, M.; Irvine, C. M. S.; Jackson, M. D.; Jacobsen, K. H.; Jahanmehr, N.; Jakovljevic, M. B.; Jauregui, A.; Javanbakht, M.; Jeemon, P.; Johansson, L. R. K.; Johnson, C. O.; Jonas, J. B.; Jürisson, M.; Kabir, Z.; Kadel, R.; Kahsay, A.; Kamal, R.; Karch, A.; Karema, C. K.; Kasaeian, A.; Kassebaum, N. J.; Kastor, A.; Katikireddi, S. V.; Kawakami, N.; Keiyoro, P. N.; Kelbore, S. G.; Kemmer, L.; Kengne, A. P.; Kesavachandran, C. N.; Khader, Y. S.; Khalil, I. A.; Khan, E. A.; Khang, Y.-H.; Khosravi, A.; Khubchandani, J.; Kiadaliri, A. A.; Kieling, 
C.; Kim, J. Y.; Kim, Y. J.; Kim, D.; Kimokoti, R. W.; Kinfu, Y.; Kisa, A.; Kissimova-Skarbek, K. A.; Kivimaki, M.; Knibbs, L. D.; Knudsen, A. K.; Kopec, J. A.; Kosen, S.; Koul, P. A.; Koyanagi, A.; Kravchenko, M.; Krohn, K. J.; Kromhout, H.; Kumar, G. A.; Kutz, M.; Kyu, H. H.; Lal, D. K.; Lalloo, R.; Lallukka, T.; Lan, Q.; Lansingh, V. C.; Larsson, A.; Lee, P. H.; Lee, A.; Leigh, J.; Leung, J.; Levi, M.; Levy, T. S.; Li, Y.; Li, Y.; Liang, X.; Liben, M. L.; Linn, S.; Liu, P.; Lodha, R.; Logroscino, G.; Looker, K. J.; Lopez, A. D.; Lorkowski, S.; Lotufo, P. A.; Lozano, R.; Lunevicius, R.; Macarayan, E. R. K.; Magdy Abd El Razek, H.; Magdy Abd El Razek, M.; Majdan, M.; Majdzadeh, R.; Majeed, A.; Malekzadeh, R.; Malhotra, R.; Malta, D. C.; Mamun, A. A.; Manguerra, H.; Mantovani, L. G.; Mapoma, C. C.; Martin, R. V.; Martinez-Raga, J.; Martins-Melo, F. R.; Mathur, M. R.; Matsushita, K.; Matzopoulos, R.; Mazidi, M.; McAlinden, C.; McGrath, J. J.; Mehata, S.; Mehndiratta, M. M.; Meier, T.; Melaku, Y. A.; Memiah, P.; Memish, Z. A.; Mendoza, W.; Mengesha, M. M.; Mensah, G. A.; Mensink, G. B. M.; Mereta, S. T.; Meretoja, T. J.; Meretoja, A.; Mezgebe, H. B.; Micha, R.; Millear, A.; Miller, T. R.; Minnig, S.; Mirarefin, M.; Mirrakhimov, E. M.; Misganaw, A.; Mishra, S. R.; Mohammad, K. A.; Mohammed, K. E.; Mohammed, S.; Mohan, M. B. V.; Mokdad, A. H.; Monasta, L.; Montico, M.; Moradi-Lakeh, M.; Moraga, P.; Morawska, L.; Morrison, S. D.; Mountjoy-Venning, C.; Mueller, U. O.; Mullany, E. C.; Muller, K.; Murthy, G. V. S.; Musa, K. I.; Naghavi, M.; Naheed, A.; Nangia, V.; Natarajan, G.; Negoi, R. I.; Negoi, I.; Nguyen, C. T.; Nguyen, Q. L.; Nguyen, T. H.; Nguyen, G.; Nguyen, M.; Nichols, E.; Ningrum, D. N. A.; Nomura, M.; Nong, V. M.; Norheim, O. F.; Norrving, B.; Noubiap, J. J. N.; Obermeyer, C. M.; Ogbo, F. A.; Oh, I.-H.; Oladimeji, O.; Olagunju, A. T.; Olagunju, T. O.; Olivares, P. R.; Olsen, H. E.; Olusanya, B. O.; Olusanya, J. O.; Opio, J. N.; Oren, E.; Ortiz, A.; Ota, E.; Owolabi, M. O.; Pa, M.; Pacella, R. E.; Pana, A.; Panda, B. K.; PandaJonas, S.; Pandian, J. D.; Papachristou, C.; Park, E.-K.; Parry, C. D.; Patten, S. B.; Patton, G. C.; Pereira, D. M.; Perico, N.; Pesudovs, K.; Petzold, M.; Phillips, M. R.; Pillay, J. D.; Piradov, M. A.; Pishgar, F.; Plass, D.; Pletcher, M. A.; Polinder, S.; Popova, S.; Poulton, R. G.; Pourmalek, F.; Prasad, N.; Purcell, C.; Qorbani, M.; Radfar, A.; Rafay, A.; Rahimi-Movaghar, A.; Rahimi-Movaghar, V.; Rahman, M. H. U.; Rahman, M. A.; Rahman, M.; Rai, R. K.; Rajsic, S.; Ram, U.; Rawaf, S.; Rehm, C. D.; Rehm, J.; Reiner, R. C.; Reitsma, M. B.; Remuzzi, G.; Renzaho, A. M. N.; Resnikoff, S.; Reynales-Shigematsu, L. M.; Rezaei, S.; Ribeiro, A. L.; Rivera, J. A.; Roba, K. T.; Rojas-Rueda, D.; Roman, Y.; Room, R.; Roshandel, G.; Roth, G. A.; Rothenbacher, D.; Rubagotti, E.; Rushton, L.; Sadat, N.; Safdarian, M.; Safi, S.; Safiri, S.; Sahathevan, R.; Salama, J.; Salomon, J. A.; Samy, A. M.; Sanabria, J. R.; Sanchez-Niño, M. D.; Sánchez-Pimienta, T. G.; Santomauro, D.; Santos, I. S.; Santric Milicevic, M. M.; Sartorius, B.; Satpathy, M.; Sawhney, M.; Saxena, S.; Schmidt, M. I.; Schneider, I. J. C.; Schutte, A. E.; Schwebel, D. C.; Schwendicke, F.; Seedat, S.; Sepanlou, S. G.; Serdar, B.; Servan-Mori, E. E.; Shaddick, G.; Shaheen, A.; Shahraz, S.; Shaikh, M. A.; Shamsipour, M.; Shamsizadeh, M.; Shariful Islam, S. M.; Sharma, J.; Sharma, R.; She, J.; Shen, J.; Shi, P.; Shibuya, K.; Shields, C.; Shiferaw, M. S.; Shigematsu, M.; Shin, M.-J.; Shiri, R.; Shirkoohi, R.; Shishani, K.; Shoman, H.; Shrime, M. G.; Sigfusdottir, I. D.; Silva, D. A. S.; Silva, J. P.; Silveira, D. G. A.; Singh, J. A.; Singh, V.; Sinha, D. N.; Skiadaresi, E.; Slepak, E. L.; Smith, D. L.; Smith, M.; Sobaih, B. H. A.; Sobngwi, E.; Soneji, S.; Sorensen, R. J. D.; Sposato, L. A.; Sreeramareddy, C. T.; Srinivasan, V.; Steel, N.; Stein, D. J.; Steiner, C.; Steinke, S.; Stokes, M. A.; Strub, B.; Subart, M.; Sufiyan, M. B.; Suliankatchi, R. A.; Sur, P. J.; Swaminathan, S.; Sykes, B. L.; Szoeke, C. E. I.; Tabarés-Seisdedos, R.; Tadakamadla, S. K.; Takahashi, K.; Takala, J. S.; Tandon, N.; Tanner, M.; Tarekegn, Y. L.; Tavakkoli, M.; Tegegne, T. K.; Tehrani-Banihashemi, A.; Terkawi, A. S.; Tesssema, B.; Thakur, J.; Thamsuwan, O.; Thankappan, K. R.; Theis, A. M.; Thomas, M. L.; Thomson, A. J.; Thrift, A. G.; Tillmann, T.; Tobe-Gai, R.; Tobollik, M.; Tollanes, M. C.; Tonelli, M.; Topor-Madry, R.; Torre, A.; Tortajada, M.; Touvier, M.; Tran, B. X.; Truelsen, T.; Tuem, K. B.; Tuzcu, E. M.; Tyrovolas, S.; Ukwaja, K. N.; Uneke, C. J.; Updike, R.; Uthman, O. A.; van Boven, J. F. M.; Varughese, S.; Vasankari, T.; Veerman, L. J.; Venkateswaran, V.; Venketasubramanian, N.; Violante, F. S.; Vladimirov, S. K.; Vlassov, V. V.; Vollset, S. E.; Vos, T.; Wadilo, F.; Wakayo, T.; Wallin, M. T.; Wang, Y.-P.; Weichenthal, S.; Weiderpass, E.; Weintraub, R. G.; Weiss, D. J.; Werdecker, A.; Westerman, R.; Whiteford, H. A.; Wiysonge, C. S.; Woldeyes, B. G.; Wolfe, C. D. A.; Woodbrook, R.; Workicho, A.; Xavier, D.; Xu, G.; Yadgir, S.; Yakob, B.; Yan, L. L.; Yaseri, M.; Yimam, H. H.; Yip, P.; Yonemoto, N.; Yoon, S.-J.; Yotebieng, M.; Younis, M. Z.; Zaidi, Z.; Zaki, M. E. S.; ZavalaArciniega, L.; Zhang, X.; Zimsen, S. R. M.; Zipkin, B.; Zodpey, S.; Lim, S. S.; Murray, C. J. L. Global, Regional, and National Comparative Risk Assessment of 84 Behavioural, Environmental and 
Occupational, and Metabolic Risks or Clusters of Risks, 1990-2016: A Systematic Analysis for the Global Burden of Disease Study 2016. The Lancet 2017, 390 (10100), 1345-1422. https://doi.org/10.1016/S0140-6736(17)32366-8.

(5) Shrivastava, M.; Cappa, C. D.; Fan, J.; Goldstein, A. H.; Guenther, A. B.; Jimenez, J. L.; Kuang, C.; Laskin, A.; Martin, S. T.; Ng, N. L.; Petaja, T.; Pierce, J. R.; Rasch, P. J.; Roldin, P.; Seinfeld, J. H.; Shilling, J.; Smith, J. N.; Thornton, J. A.; Volkamer, R.; Wang, J.; Worsnop, D. R.; Zaveri, R. A.; Zelenyuk, A.; Zhang, Q. Recent Advances in Understanding Secondary Organic Aerosol: Implications for Global Climate Forcing: Advances in Secondary Organic Aerosol. Reviews of Geophysics 2017, 55 (2), 509-559. https://doi.org/10.1002/2016RG000540.

(6) Jimenez, J. L.; Canagaratna, M. R.; Donahue, N. M.; Prevot, A. S. H.; Zhang, Q.; Kroll, J. H.; DeCarlo, P. F.; Allan, J. D.; Coe, H.; Ng, N. L.; Aiken, A. C.; Docherty, K. S.; Ulbrich, I. M.; Grieshop, A. P.; Robinson, A. L.; Duplissy, J.; Smith, J. D.; Wilson, K. R.; Lanz, V. A.; Hueglin, C.; Sun, Y. L.; Tian, J.; Laaksonen, A.; Raatikainen, T.; Rautiainen, J.; Vaattovaara, P.; Ehn, M.; Kulmala, M.; Tomlinson, J. M.; Collins, D. R.; Cubison, M. J.; E.; Dunlea, J.; Huffman, J. A.; Onasch, T. B.; Alfarra, M. R.; Williams, P. I.; Bower, K.; Kondo, Y.; Schneider, J.; Drewnick, F.; Borrmann, S.; Weimer, S.; Demerjian, K.; Salcedo, D.; Cottrell, L.; Griffin, R.; Takami, A.; Miyoshi, T.; Hatakeyama, S.; Shimono, A.; Sun, J. Y.; Zhang, Y. M.; Dzepina, K.; Kimmel, J. R.; Sueper, D.; Jayne, J. T.; Herndon, S. C.; Trimborn, A. M.; Williams, L. R.; Wood, E. C.; Middlebrook, A. M.; Kolb, C. E.; Baltensperger, U.; Worsnop, D. R. Evolution of Organic Aerosols in the Atmosphere. Science 2009, 326 (5959), 1525-1529. https://doi.org/10.1126/science.1180353.

(7) Ibach, H. Physics of Surfaces and Interfaces; Springer: Berlin; New York, 2006.

(8) Drljaca, A.; Hubbard, C. D.; van Eldik, R.; Asano, T.; Basilevsky, M. V.; le Noble, W. J. Activation and Reaction Volumes in Solution. 3. Chemical Reviews 1998, 98 (6), 2167-2290. https://doi.org/10.1021/cr970461b.

(9) Laidler, K. J.; King, M. C. Development of Transition-State Theory. J. Phys. Chem. 1983, 87 (15), 2657-2664. https://doi.org/10.1021/j100238a002.

(10) Chen, B.; Hoffmann, R.; Cammi, R. The Effect of Pressure on Organic Reactions in Fluids-a New Theoretical Perspective. Angew. Chem. Int. Ed. 2017, 56 (37), 11126-11142. https://doi.org/10.1002/anie.201705427.

(11) Fu, T.-M.; Jacob, D. J.; Wittrock, F.; Burrows, J. P.; Vrekoussis, M.; Henze, D. K. Global Budgets of Atmospheric Glyoxal and Methylglyoxal, and Implications for Formation of Secondary Organic Aerosols. Journal of Geophysical Research 2008, 113 (D15). https://doi.org/10.1029/2007JD009505.

(12) Galloway, M. M.; Chhabra, P. S.; Chan, A. W. H.; Surratt, J. D.; Flagan, R. C.; Seinfeld, J. H.; Keutsch, F. N. Glyoxal Uptake on Ammonium Sulphate Seed Aerosol: Reaction Products and Reversibility of Uptake under Dark and Irradiated Conditions. Atmos. Chem. Phys. 2009, 9 (10), 3331-3345. https://doi.org/10.5194/acp-9-3331-2009.

(13) Liggio, J. Reactive Uptake of Glyoxal by Particulate Matter. J. Geophys. Res. 2005, 110 (D10), D10304. https://doi.org/10.1029/2004JD005113.

(14) Kroll, J. H.; Ng, N. L.; Murphy, S. M.; Varutbangkul, V.; Flagan, R. C.; Seinfeld, J. H. Chamber Studies of Secondary Organic Aerosol Growth by Reactive Uptake of Simple Carbonyl Compounds. J. Geophys. Res. 2005, 110 (D23), D23207. https://doi.org/10.1029/2005JD006004. (15) Corrigan, A. L.; Hanley, S. W.; De Haan, D. O. Uptake of Glyoxal by Organic and Inorganic Aerosol. Environ. Sci. Technol. 2008, 42 (12), 4428-4433. https://doi.org/10.1021/es7032394.

(16) Haan, D. O. D.; Corrigan, A. L.; Smith, K. W.; Stroik, D. R.; Turley, J. J.; Lee, F. E.; Tolbert, M. A.; Jimenez, J. L.; Cordova, K. E.; Ferrell, G. R. Secondary Organic Aerosol-Forming Reactions of Glyoxal with Amino Acids. Environ. Sci. Technol. 2009, 43 (8), 2818-2824. https://doi.org/10.1021/es803534f.

(17) Ervens, B.; Volkamer, R. Glyoxal Processing by Aerosol Multiphase Chemistry: Towards a Kinetic Modeling Framework of Secondary Organic Aerosol Formation in Aqueous Particles. Atmos. Chem. Phys. 2010, 10 (17), 8219-8244. https://doi.org/10.5194/acp-10-8219-2010.

(18) Trainic, M.; Abo Riziq, A.; Lavi, A.; Flores, J. M.; Rudich, Y. The Optical, Physical and Chemical Properties of the Products of Glyoxal Uptake on Ammonium Sulfate Seed Aerosols. Atmos. Chem. Phys. 2011, 11 (18), 9697-9707. https://doi.org/10.5194/acp-11-9697-2011.

(19) Yu, G.; Bayer, A. R.; Galloway, M. M.; Korshavn, K. J.; Fry, C. G.; Keutsch, F. N. Glyoxal in 
Aqueous Ammonium Sulfate Solutions: Products, Kinetics and Hydration Effects. Environmental Science \& Technology 2011, 45 (15), 6336-6342. https://doi.org/10.1021/es200989n.

(20) Nozière, B.; Dziedzic, P.; Córdova, A. Products and Kinetics of the Liquid-Phase Reaction of Glyoxal Catalyzed by Ammonium Ions $\left(\mathrm{NH}_{4}{ }^{+}\right)$. The Journal of Physical Chemistry A 2009, 113 (1), 231-237. https://doi.org/10.1021/jp8078293.

(21) Rossignol, S.; Aregahegn, K. Z.; Tinel, L.; Fine, L.; Nozière, B.; George, C. Glyoxal Induced Atmospheric Photosensitized Chemistry Leading to Organic Aerosol Growth. Environmental Science \& Technology 2014, 48 (6), 3218-3227. https://doi.org/10.1021/es405581g.

(22) Herrmann, H.; Schaefer, T.; Tilgner, A.; Styler, S. A.; Weller, C.; Teich, M.; Otto, T.

497

498

499

500

501

502

503

504

505

506

507

508

509

510

511

512

513

514

515

516

517

518

519

520

521

522

523

524

525

526

527

528

529

530

531

532

533

534

535

536

537

538

539

540

541

542

Tropospheric Aqueous-Phase Chemistry: Kinetics, Mechanisms, and Its Coupling to a Changing Gas Phase. Chemical Reviews 2015, 115 (10), 4259-4334. https://doi.org/10.1021/cr500447k.

(23) Volkamer, R.; San Martini, F.; Molina, L. T.; Salcedo, D.; Jimenez, J. L.; Molina, M. J. A Missing Sink for Gas-Phase Glyoxal in Mexico City: Formation of Secondary Organic Aerosol. Geophys. Res. Lett. 2007, 34 (19), L19807. https://doi.org/10.1029/2007GL030752.

(24) Kampf, C. J.; Jakob, R.; Hoffmann, T. Identification and Characterization of Aging Products in the Glyoxal/Ammonium Sulfate System \&ndash; Implications for Light-Absorbing Material in Atmospheric Aerosols. Atmos. Chem. Phys. 2012, 12 (14), 6323-6333. https://doi.org/10.5194/acp-126323-2012.

(25) McNeill, V. F.; Woo, J. L.; Kim, D. D.; Schwier, A. N.; Wannell, N. J.; Sumner, A. J.; Barakat, J. M. Aqueous-Phase Secondary Organic Aerosol and Organosulfate Formation in Atmospheric Aerosols: A Modeling Study. Environmental Science \& Technology 2012, 46 (15), 8075-8081. https://doi.org/10.1021/es3002986.

(26) Tsui, W. G.; Woo, J. L.; McNeill, V. F. Impact of Aerosol-Cloud Cycling on Aqueous Secondary Organic Aerosol Formation. Atmosphere 2019, 10 (11), 666.

https://doi.org/10.3390/atmos10110666.

(27) Woo, J. L.; Kim, D. D.; Schwier, A. N.; Li, R.; McNeill, V. F. Aqueous Aerosol SOA Formation: Impact on Aerosol Physical Properties. Faraday Discuss. 2013, 165, 357.

https://doi.org/10.1039/c3fd00032j.

(28) Schwier, A. N.; Sareen, N.; Mitroo, D.; Shapiro, E. L.; McNeill, V. F. Glyoxal-Methylglyoxal Cross-Reactions in Secondary Organic Aerosol Formation. Environ. Sci. Technol. 2010, 44 (16), 6174-6182. https://doi.org/10.1021/es101225q.

(29) Hritz, A. D.; Raymond, T. M.; Dutcher, D. D. A Method for the Direct Measurement of Surface Tension of Collected Atmospherically Relevant Aerosol Particles Using Atomic Force Microscopy. Atmospheric Chemistry and Physics 2016, 16 (15), 9761-9769.

https://doi.org/10.5194/acp-16-9761-2016.

(30) Bzdek, B. R.; Power, R. M.; Simpson, S. H.; Reid, J. P.; Royall, C. P. Precise, Contactless Measurements of the Surface Tension of Picolitre Aerosol Droplets. Chem. Sci. 2016, 7 (1), 274-285. https://doi.org/10.1039/C5SC03184B.

(31) Gray Bé, A.; Upshur, M. A.; Liu, P.; Martin, S. T.; Geiger, F. M.; Thomson, R. J. Cloud Activation Potentials for Atmospheric $\alpha$-Pinene and $\beta$-Caryophyllene Ozonolysis Products. ACS Cent. Sci. 2017, 3 (7), 715-725. https://doi.org/10.1021/acscentsci.7b00112.

(32) Schwier, A. N.; Viglione, G. A.; Li, Z.; Faye McNeill, V. Modeling the Surface Tension of Complex, Reactive Organic-Inorganic Mixtures. Atmos. Chem. Phys. 2013, 13 (21), 10721-10732. https://doi.org/10.5194/acp-13-10721-2013.

(33) Shapiro, E. L.; Szprengiel, J.; Sareen, N.; Jen, C. N.; Giordano, M. R.; McNeill, V. F. LightAbsorbing Secondary Organic Material Formed by Glyoxal in Aqueous Aerosol Mimics. Atmos. Chem. Phys. 2009, 9 (7), 2289-2300. https://doi.org/10.5194/acp-9-2289-2009.

(34) Bateman, A. P.; Gong, Z.; Liu, P.; Sato, B.; Cirino, G.; Zhang, Y.; Artaxo, P.; Bertram, A. K.; Manzi, A. O.; Rizzo, L. V.; Souza, R. A. F.; Zaveri, R. A.; Martin, S. T. Sub-Micrometre Particulate Matter Is Primarily in Liquid Form over Amazon Rainforest. Nature Geoscience 2016, 9 (1), 34-37. https://doi.org/10.1038/ngeo2599.

(35) Cappa, C. D.; Wilson, K. R. Evolution of Organic Aerosol Mass Spectra upon Heating: Implications for OA Phase and Partitioning Behavior. Atmospheric Chemistry and Physics 2011, 11 (5), 1895-1911. https://doi.org/10.5194/acp-11-1895-2011.

(36) Virtanen, A.; Joutsensaari, J.; Koop, T.; Kannosto, J.; Yli-Pirilä, P.; Leskinen, J.; Mäkelä, J. 
M.; Holopainen, J. K.; Pöschl, U.; Kulmala, M.; Worsnop, D. R.; Laaksonen, A. An Amorphous Solid 


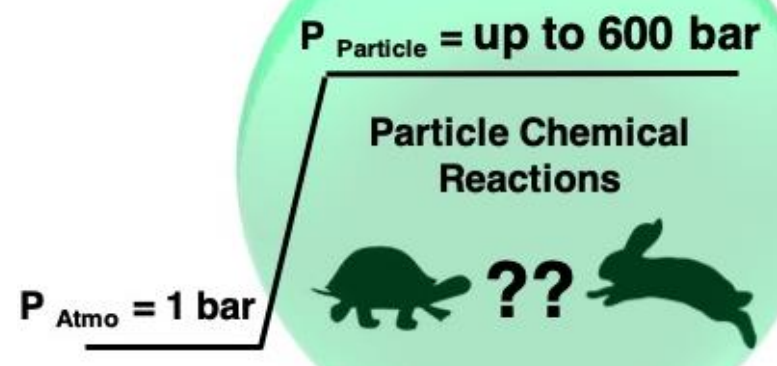

599 